\title{
A CHOICE OF THE OPTIMUM CUTTING RANGES FOR CUTTING NOZZLES A-SD FOR SELECTION OF METALLURGICAL MATERIAL
}

\author{
Dana Stančeková', Anna Rudawska², Albert Kulla', Jana Petrư ${ }^{3}$, Jozef Holubják ${ }^{1}$
}

1 University of Žilina, Faculty of Mechanical Engineering, Univerzitna 1, 010 26, Žilina, Slovakia, e-mail: dana. stancekova@fstroj.uniza.sk, albert.kulla@uniza.sk, jozef.Holubjak@fstroj.uniza.sk

2 Lublin University of Technology, Faculty of Mechanical Engineering, ul. Nadbystrzycka 36, 20-618 Lublin, Poland, e-mail: a.rudawska@pollub.pl

3 VSB -TU Ostrava, Faculty of Mechanical Engineering, 17. listopadu 15/2172, 70833 Ostrava, Czech Republic, e-mail: jana.petru@vsb.cz

Received: 2018.05.16 Accepted: 2018.08.01 Published: 2018.09.01

\begin{abstract}
On the market there are plenty of machines for cutting of steel via a mixture of oxygen and flammable gases. Various manufacturers provide several types of torches, cutting nozzles and other equipment in their product range. Cutting nozzles are a component that significantly affects quality of cutting based in set parameters. However, data from catalogues and manuals by manufacturers on cutting parameters of nozzles are rarely in use in real conditions. That is why optimum cutting conditions for cutting via nozzles A-SD made by RHONA were tested and the final results were compared with those in the catalogue for a proper use in practice.
\end{abstract}

Keywords: cutting nozzles, data from catalogues, cutting parameters, final results.

\section{INTRODUCTION}

Thermal division of materials by means of a use of a flammable gas and oxygen is one of the oldest technologies of thermal material divisions. Even at present, when technologies of material division with a use of a laser beam or plasm are on the rise, an oxygen cutting process takes an important position in the hierarchy of thermal material division. There exist manifold equipment for steel cutting using a mixture of combustible gas and oxygen on the market. Various producers offer differenttypes of torches, cutting nozzles and other equipment as a part of their portfolio. They are cutting nozzles which are a component which affects quality of cutting most significantly based on selected cutting parameters $[17,3,15]$. Price and cutting parameters of nozzles are the most important parameters for users of this technology. As far as practice concerned, it is not an easy task to distinguish clearly their cutting parameters according to values stated in catalogues. Catalogue parameters promoted by producers are parameters measured in laboratory conditions. This fact causes that producers of cutting semiproducts from steel pre-fabrication are forced to select optimal cutting proportions for cutting nozzles in real amateurish conditions. A similar issue was solved by a company for which the below-stated experimental verifications were performed $[17,14,16]$.

Thermal division of materials, frequently perceivedas an oxygen cutting process, is still a relevant technology, which is widely used in various areas of production. Despite still more frequent application of plasma and laser technologies in a sphere of division and preparation of material, it still has its solid position in material division which exceed thickness of $50 \mathrm{~mm}[5,10]$.

The principle of technology of cutting of metal materials by a torch (Fig. 1), is a process of burning steel heated up to an ignition temperature 


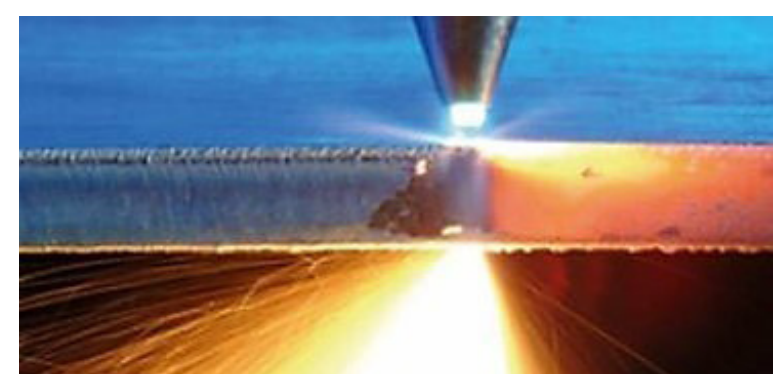

Fig. 1. Thermal flame cutting of materials

in an oxygen flow. For a thermal flame cutting a mixture of oxygen and a flammable gas is used. This process is based on a principle of oxydation, which uses a thermal effect from this reaction and serves in the first phase for melting of a metal material by a heating flame $[5,18,12]$.

These days, research in an area of steel cutting focuses on development of cutting nozzles for particular thickness of materials and various types of heating flames.

\section{A PROCESS OF TESTING OF CUTTING NOZZLES A-SD}

Cutting nozzles have the greatest impact on quality of a cut and cutting performance. An optimal selection of parameters of cutting, such as pressures of particular gases, speed of cutting, a selection of a correct nozzle for a given thickness, a height of a nozzle over a surface of the cut materials have a major impact on quality of cut surfaces together with a selected procedure that burns up materials. From a technological standpoint, a priority between quality of a cut and cutting performance is selected $[18,12]$.

Cutting performance is an important factor for mass production in a gross division of largescale semiproducts in which requirements for accuracy and quality of cut surfaces are lower. On the other hand, a single-part production exactly defines requirements for uprightness and quality of cut surfaces for needs of further machining processes, welding or thermal processing.

For the required quality of cut surfaces a selection of optimal cutting rates is necessary. They are often different for catalague ones, preferred by producers of cutting nozzles and torches. Catalogue parameters for individual torches are frequently a result of experiments in laboratory conditions that differ significantly from real conditions in production. In practice, we often come across the fact that cutting with a use of catalogue values and parameters cause striking poor quality of cut surfaces in a form of deflections from uprightness, ripple or deep grooving in surfaces.

The most frequent reasons of these deformations are: too high speed of cutting, high pressures of cutting oxygen, a short distance of the nozzle from a material.

A selection of optimal cutting proportions for cutting nozzles A-SD in a use of a machine cutting torch BIR $+\mathrm{A} 32 / 320$ by the company RHONA was performed for the needs of the com-pany[13,7]. The aim of the research was to select an optimal cutting ratio for cutting nozzles A-SD for requirements of output quality of cut surfaces $[8,1]$.

\section{A description of cutting equipment CNC Pierce SCORPION 2500}

A process of a selection of optimal cutting ratio for machine oxygen and acetylene cutting was performed by an application of the cutting equipment CNC Pierce SCORPION 2500, fig. 2. It is a light portal cutting machine for autogeneous and plasma cutting with a good ratio of performance to price. It is valued for its easy operation and maintenance, even in difficult performing conditions $[6,9,2]$.

\section{A description of a machine torch $\mathrm{BIR}+\mathrm{A}$ $32 / 320$}

A machine cutting torch BIR+ A 32/320 (Fig. 3 ) is designed for steel cutting by means of a heating flame formed by a mixture of oxygen and a technical gas together with a flow of cutting oxygen for thickness $3-300 \mathrm{~mm}$. For individual thickness of a plate for the torch BIR+A 32/320 nozzles are selected and applied according to a range for concrete thicknesses of non-alloy steel or low-alloy steel.Individual nozzles are at the same time selected according to a used technical gas $[6,11]$.

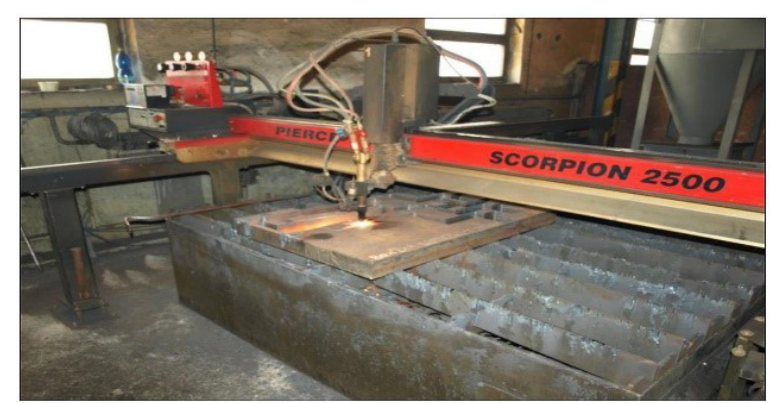

Fig. 2. The cutting machine CNC Pierce SCORPION 2500 


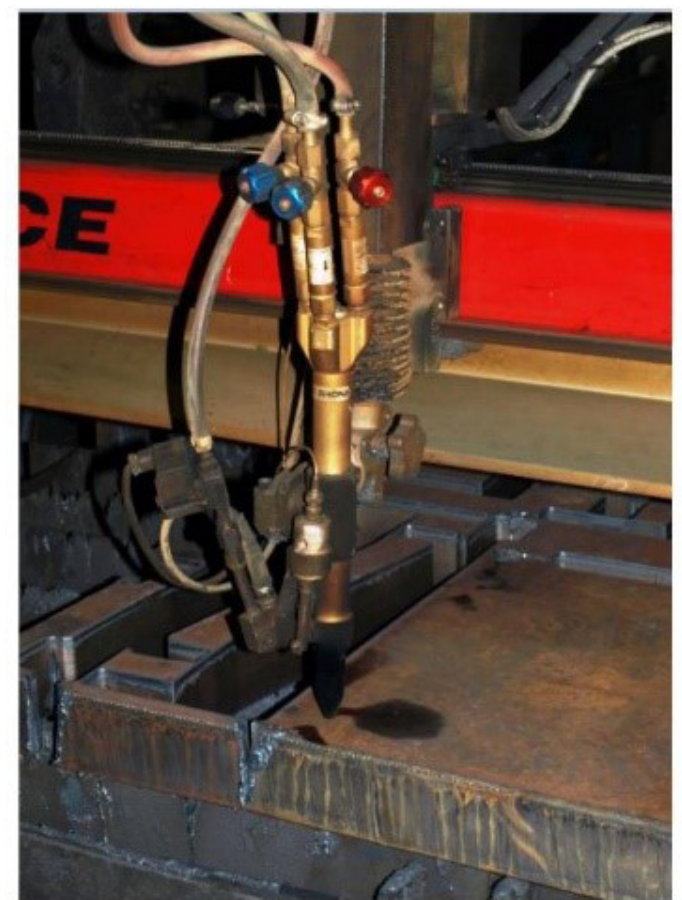

Fig. 3. The machine cutting torch $B I R+A$ 32/220 during technological preparation

\section{Cutting nozzles A-SD}

For needs of research, nozzles A-SD by RHONA were used, fig. 4. The nozzles A-SD are classified according to a range of thicknesses for application on particular plate thickness. Individual nozzles have a specified distance of the nozzle from material and a width of a kerf. The producer sets further specifications for individual thicknesses of plate and a theoretical cutting speed which was tested.

The process of testing of cutting nozzles A-SD followed the systematical use of nozzles in cutting of semiproducts according to a cutting drawing based on a standard order, fig. 5. To test the nozzles, catalogue cutting ratio for individual ranges and thickness of cut material were applied. Cut semiproducts underwent a study of uprightness of the cut surface and a visual check of flatness of cut surfaces. a)

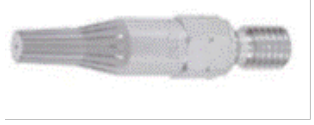

b)

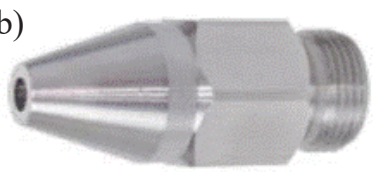

Fig. 4. Nozzles A-SD 10 by the company RHONA a) a cutting part, b) a heating part [4]

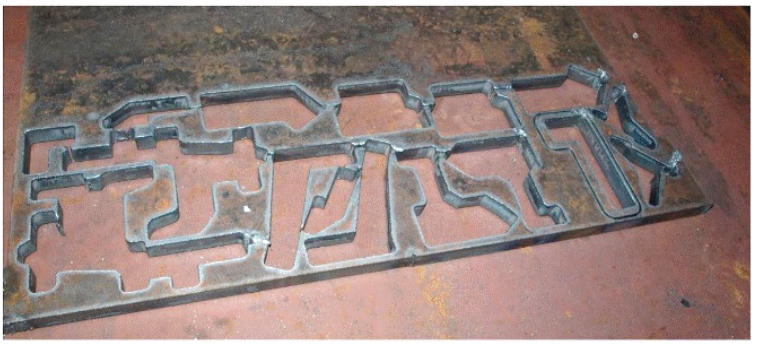

Fig. 5. A position of cuts of semiproducts (according to a drawing) - a burnt out part of a plate

Requirements of quality of cut surfaces are as follows:

- potential small-scale cutting striations are evenly spread perpendicular to a direction of cutting,

- debris which eventually adhered on the upper part of a cut is easily removed,

- a cut surface is so flat that does not require further machining.

Nozzles A-SD were tested on materials: steel $\mathrm{C} 45+\mathrm{N}$ with thickness $20,25,30,40,50,60,80$, $100 \mathrm{~mm}$.

An attachment of a nozzle on a torch. Before starting off a cutting process it is necessary to attach a proper nozzle on the torch, following the range indicated by a producer. In a range on the limit of a use of a nozzle for a given plate thickness the nozzles with a wider range were selected assuming higher quality of a cut.

An adjustment of gas pressures is stated in bars for cutting oxygen, heating oxygen and acetylene is performed on the control panel by means of valves. When it is necessary to set a more accurate adjustment of pressure, especially in case of acetylene, it is possible to perform this slight adjustment right on the torch before the entrance of a torch mixer. Individual pressures were set according to table 1 from the catalogue in which there are stated values of pressures for individual gases according to the producer.

Upright adjustment of a torch, Fig. 6. A control of upright adjustement towards the cut steel sheet is a very important step before the initiation of a cutting process. It is necessary to maintain the same distance of the nozzle from material.

Steel plate burning was performed on a free space of the sheet, or its edge. In case of material with thickness above $80 \mathrm{~mm}$ (included), the process of burning was performed on its edge 
Table 1. Catalogue values for nozzles A-SD [4]

\begin{tabular}{|c|c|c|c|c|c|c|c|}
\hline \multirow{2}{*}{$\begin{array}{c}\text { Range } \\
\text { nozzles } \\
(\mathrm{mm})\end{array}$} & \multirow{2}{*}{$\begin{array}{c}\text { Thic-kness } \\
\text { of material } \\
\qquad(\mathrm{mm})\end{array}$} & \multirow{2}{*}{$\begin{array}{l}\text { Cutting } \\
\text { speed } \\
100 \% 85 \% \\
\left(\mathrm{~mm} \cdot \mathrm{min}^{-1}\right)\end{array}$} & \multirow{2}{*}{$\begin{array}{c}\text { Distance } \\
\text { nozzles of } \\
\text { material } \\
(\mathrm{mm})\end{array}$} & \multirow{2}{*}{$\begin{array}{l}\text { Width of the } \\
\text { kerf } \\
(\mathrm{mm})\end{array}$} & \multicolumn{3}{|c|}{ Gas pressures (bar) } \\
\hline & & & & & $\begin{array}{l}\text { Cutting } \\
\text { oxygen }\end{array}$ & $\begin{array}{l}\text { Heating } \\
\text { oxygen }\end{array}$ & Acetylene \\
\hline \multirow{4}{*}{$10-25$} & 10 & $650 / 550$ & $5-7$ & 2.1 & 6.5 & 2.5 & 0.5 \\
\hline & 15 & $600 / 500$ & $5-7$ & 2.1 & 6.5 & 2.5 & 0.5 \\
\hline & 20 & $550 / 470$ & $5-7$ & 2.1 & 7.0 & 2.5 & 0.5 \\
\hline & 25 & $500 / 420$ & $5-7$ & 2.1 & 7.5 & 2.5 & 0.5 \\
\hline \multirow{4}{*}{$25-40$} & 25 & $500 / 420$ & $5-7$ & 2.5 & 6.5 & 2.5 & 0.5 \\
\hline & 30 & $480 / 400$ & $5-7$ & 2.6 & 7.5 & 2.5 & 0.5 \\
\hline & 35 & $450 / 380$ & $5-7$ & 2.7 & 7.5 & 2.5 & 0.5 \\
\hline & 40 & $420 / 360$ & $5-7$ & 2.7 & 8.0 & 2.5 & 0.5 \\
\hline \multirow{3}{*}{$40-60$} & 40 & $420 / 360$ & $5-7$ & 2.8 & 6.5 & 2.5 & 0.5 \\
\hline & 50 & $390 / 330$ & $5-7$ & 2.9 & 7.0 & 2.5 & 0.5 \\
\hline & 60 & $360 / 300$ & $5-7$ & 3.0 & 8.5 & 2.5 & 0.5 \\
\hline \multirow{3}{*}{$60-100$} & 60 & $360 / 300$ & $5-7$ & 3.0 & 6.5 & 2.5 & 0.5 \\
\hline & 80 & $310 / 260$ & $5-7$ & 3.0 & 7.5 & 2.5 & 0.5 \\
\hline & 100 & $270 / 230$ & $5-7$ & 3.0 & 8.0 & 2.5 & 0.5 \\
\hline
\end{tabular}

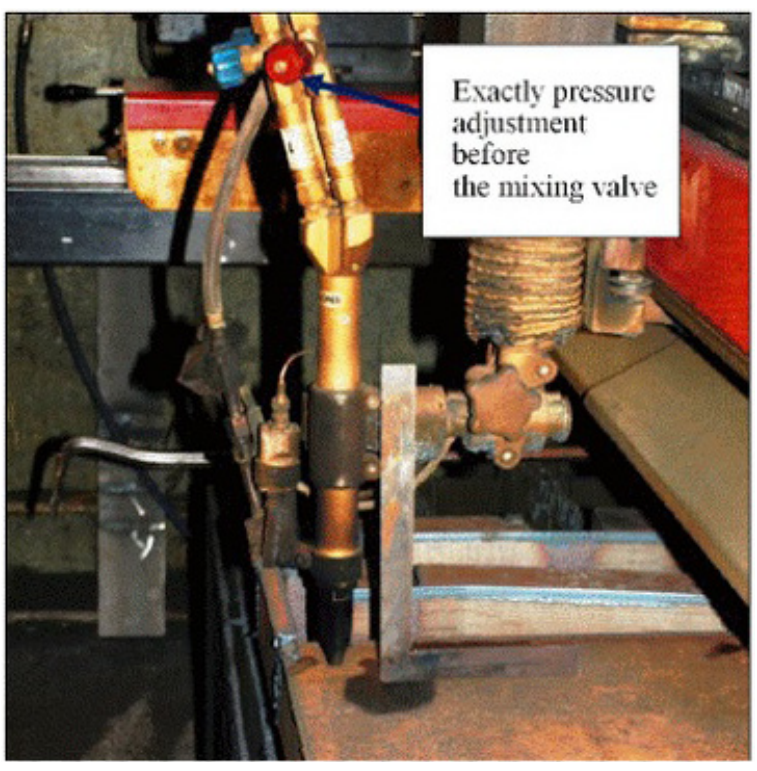

Fig. 6. A control of upright adjustment of the torch

to avoid damage on the steel plate caused by bursting off its adjusted parts. For individual thicknesses of steel plate distances of motions of torches during burning up were selected. It is the distance which the torch passes from the spot of the start of burning process up to the spot of burning up of the steel plate itself. The distances were selected with respect to a shape, position of a semiproduct and thickness. Time intervals of preheating were selected for given thicknesses, according to Table 2 .
Table 2. Time intervals of preheating for individual thicknesses

\begin{tabular}{|c|c|c|c|c|}
\hline thickness of plate $(\mathrm{mm})$ & $\mathbf{6 - 2 0}$ & $\mathbf{2 0 - 6 0}$ & $\mathbf{6 0 - 8 0}$ & $\begin{array}{c}\text { above } \\
\mathbf{8 0}\end{array}$ \\
\hline time of preheating (s) & 15 & 30 & 40 & 50 \\
\hline
\end{tabular}
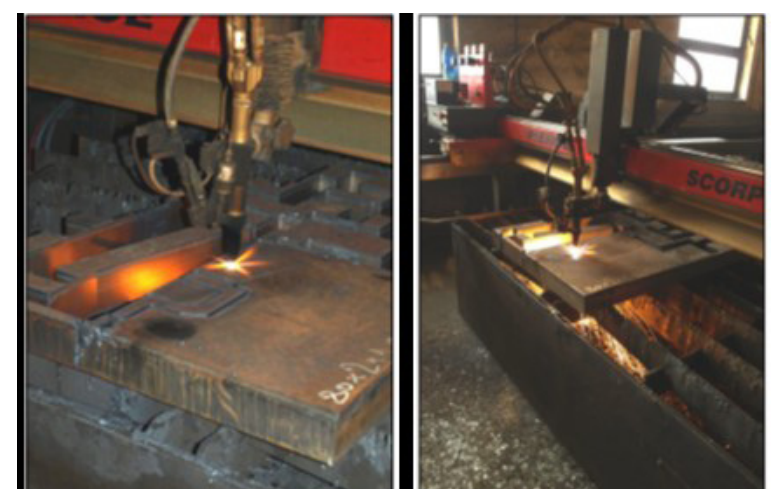

Fig. 7. Steel cutting, thickness $80 \mathrm{~mm}$

Cutting of semiproducts. After burning through the steel plate, cutting parameters were selected according to Table 2 and given instructions for a control unit. The cutting speed was set according to parameters of $85 \%$ of cutting speed from Table 1. Consequently, cutting started, Figure 7, according to a cutting layout. The cut semiproducts were gradually selected, classified and evaluated according to quality of cut-out surface. 


\section{THE CHOICE OF OPTIMAL CUTTING PROPORTIONS FOR CUTTING NOZZLES A-SD AND THEIR APPLICATION IN PRACTICE}

After completion of cutting semiproducts according the cutting layout were individual pieces selected from a cut steel plate. Cut off semiproducts were classified according to thickness of metal plate and type of steel and consequently surface and uprightness of cut surface were evaluated. Uprightness of the cut surface was compared with a square and the surface of the cut area was evaluated visually.

Requirements for uprightness of the cut area and the surface of the cut steel plate was set in such a way that a deviation of a supporting surface of the square can not exceed $1 \mathrm{~mm}$ per $100 \mathrm{~mm}$. Surface of the cut area had to meet standards of smooth surface, as mentioned in Fig. 8. The surface of cut area is supposed to be without scoring caused by cutting oxygen, various deformations or meltings and without rounding off the cuting edge.

\section{Deformations caused by cutting of steel semiproducts according to catalogue cutting proportions for nozzles A-SD}

In Figure 9, the angle $\alpha$ represents deviations of uprightness of a cut area to the metal sheet sur-

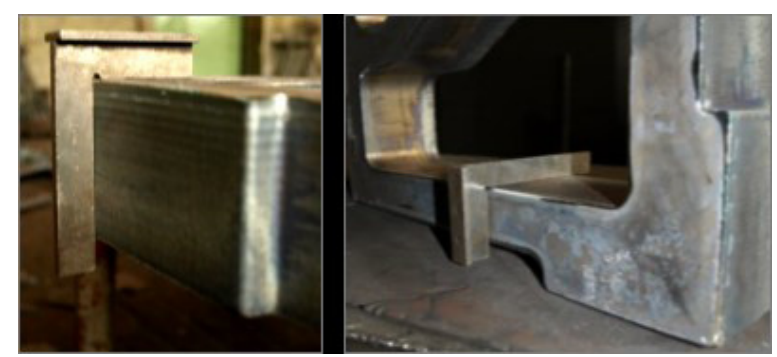

Fig. 8. Uprightness of peripheral surface, thickness of $100 \mathrm{~mm}$
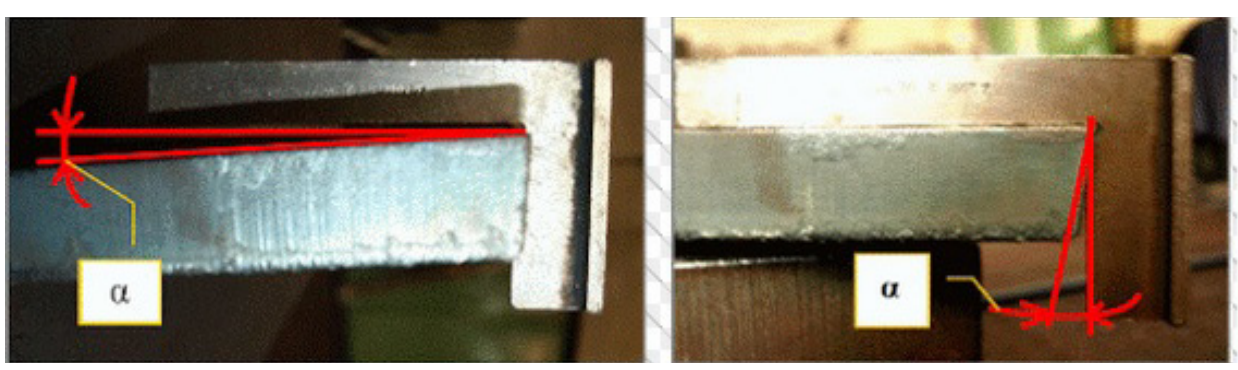

Fig. 9. Deviations of uprightness, thickness $20 \mathrm{~mm}$. Upright deviations, thickness $20 \mathrm{~mm}$

Fig. 10. A molten upper edge, thickness $20 \mathrm{~mm}$

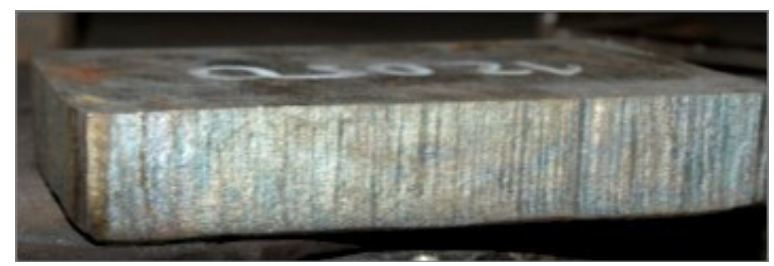

Fig. 11. The scored cut, $20 \mathrm{~mm}$ sheet $20 \mathrm{~mm}$ exceeded in case of acetylene $25 \%$ resulting optimal cutting proportions. High presof the material surface. for optimal cutting speed.

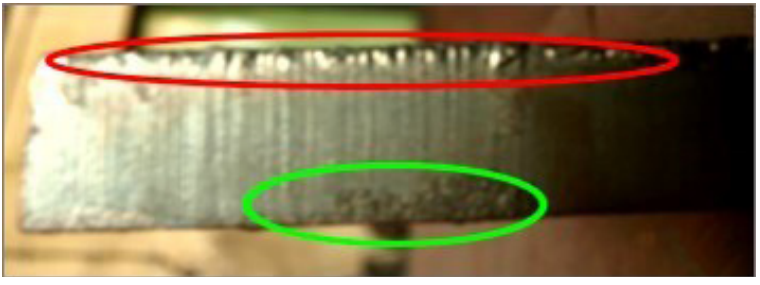

face, which was caused by excessive cutting speed and a long distance of the nozzle from the material.

In Fig. 10 one may see a place of oxidation marked by a green ellipse. It probably originated by a clogging of the nozzle during repeated operations. The red ellipse marks a melted upper edge of the cut which was caused by high pressure of heating oxygen and acetylene. Catalogue parameters of pressures of gases in thickness of metal and in the case of oxygen, even up to $39 \%$ against sure of a heating flame caused excessive melting

Visible scoring in the cut surface of the workpiece caused by slow cutting speed and a long distance of the nozzle from the material surface are shown in Fig. 11. Scorings on the cut area were caused by the cutting speed of $330 \mathrm{~mm} \times \mathrm{min}-1$ and the result was too slow speed for searching 


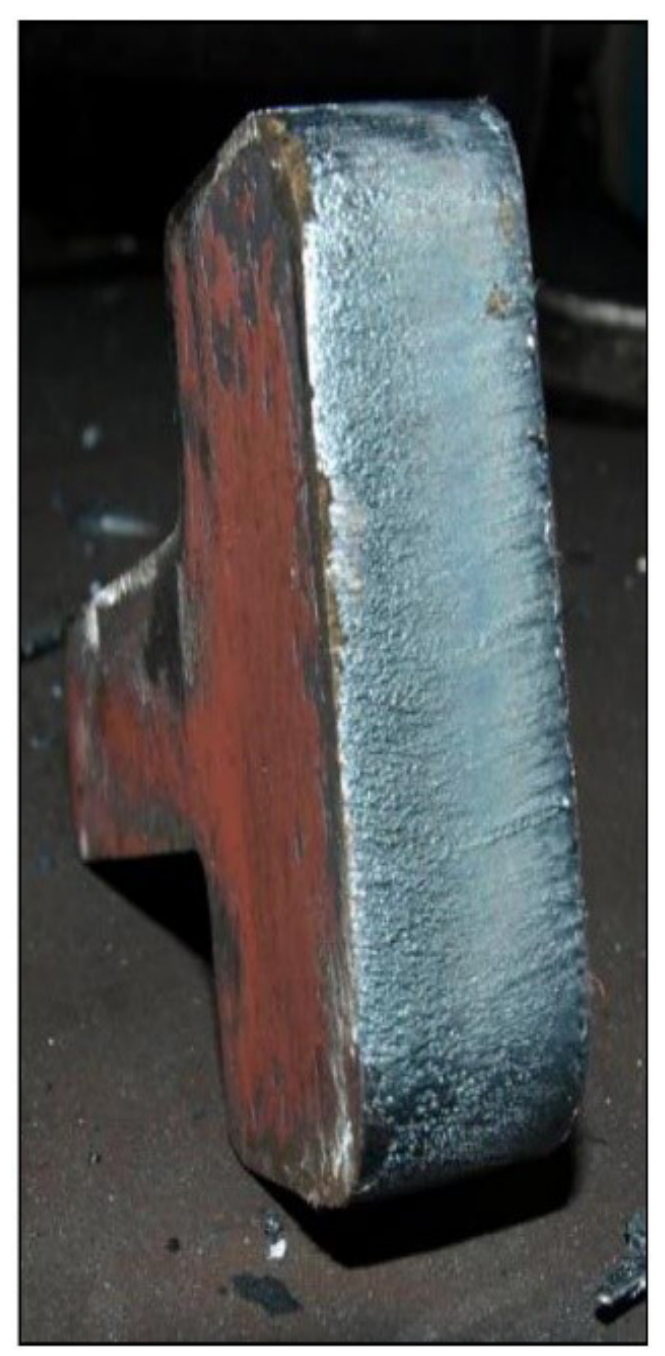

Fig. 12. Oxide-based balls in a lower part of the cut surface and scoring on the upper cut area, thickness $30 \mathrm{~mm}$

A semiproduct in Fig. 12 contains adjusted miniature oxide-based balls in the lower part and in the upper part there appear sidelong scorings which arethe result of the cutting speed of 420 $\mathrm{mm} \cdot \mathrm{min}^{-1}$.
The above-stated deformations were caused by an interaction of high pressure of a heating flame in which values of pressures of gases exceeded optimal values by approx. $25 \%$. Bonded iron oxides may indicate a low pressure of cutting oxygen but these cases were not proven.

\section{Quality of cut surface}

The required quality of the cut surface before final grinding of edges is shown in Fig. 13 and minor melting of the upper part of the cut will be removed by grinding, the lower edge is perfectly sharp. The final effect was reached following modifications of cutting parameters according to generally accepted conditions for machine acetylene cutting. Gradually selected parameters for individual thickness of steel sheet were also modified. Then, cutting of individual semiproducts and measurement of quality of cut surface followed. Following this, a form of optimal cutting proportions for machine oxygene cutting for individual material thicknesses wasobtained. Optimal cutting proportions by means of which we reached the required results of the cut surfaces of individual semiproducts are stated in Table 3. The stated cutting proportions can be used in practice for oxygene and acetylene steel cutting.

\section{CONCLUSIONS}

\section{Scientifically established facts during testing of nozzles A-SD}

Quality measurement of individual cut surfaces of semiproducts shows that catalog cutting parameters caused mistakes in cutting surfaces due to high speed of cutting and high pressure of heating flames. The most frequent mistakes are:

- deviations in uprightness of cut surfaces,

- deviations of parameters of width of a cutting kerf,

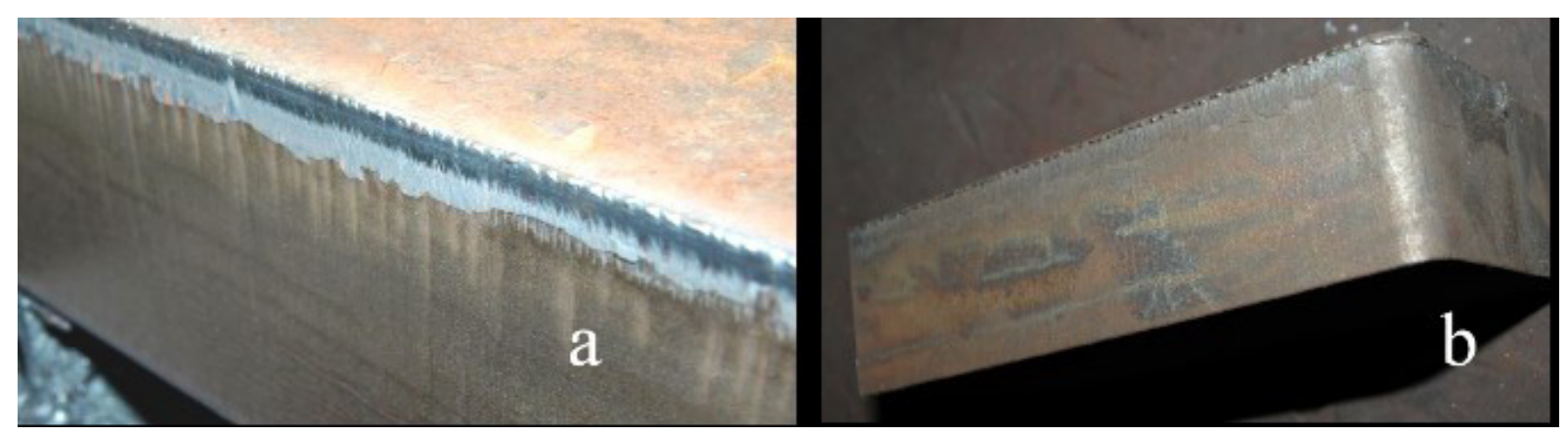

Fig. 13. Required cut quality before grinding of edges, steel $\mathrm{C} 45+\mathrm{N}$ a)thickness $100 \mathrm{~mm}$, b) $40 \mathrm{~mm}$ 
Table 3. Optimal cutting proportions for nozzles A-SD

\begin{tabular}{|c|c|c|c|c|c|c|c|}
\hline \multirow{2}{*}{$\begin{array}{l}\text { Thickness } \\
\text { of material } \\
\qquad(\mathrm{mm})\end{array}$} & \multirow{2}{*}{$\begin{array}{c}\text { Range } \\
\text { nozzles } \\
(\mathrm{mm})\end{array}$} & \multirow{2}{*}{$\begin{array}{l}\text { Cutting } \\
\text { speed } \\
\left(\mathrm{mm} \cdot \mathrm{min}^{-1}\right)\end{array}$} & \multirow{2}{*}{$\begin{array}{l}\text { Preheating } \\
\text { time (s) }\end{array}$} & \multirow{2}{*}{$\begin{array}{l}\text { Width of the } \\
\text { kerf } \\
(\mathrm{mm})\end{array}$} & \multicolumn{3}{|c|}{ Gas pressures (bar) } \\
\hline & & & & & $\begin{array}{l}\text { Cutting } \\
\text { oxygen }\end{array}$ & $\begin{array}{l}\text { Heating } \\
\text { oxygen }\end{array}$ & Acetylene \\
\hline 20 & $10-25$ & 380 & 15 & 2.7 & 5.5-6.5 & 1.8 & 0.4 \\
\hline 25 & $25-40$ & 350 & 15 & 2.7 & 5.5-6.5 & $1.8-2$ & 0.4 \\
\hline 30 & $25-40$ & 320 & 20 & 2.7 & $5.5-6.5$ & $1.8-2$ & 0.4 \\
\hline 40 & $40-60$ & 290 & 30 & 2.8 & $5.5-6.5$ & $1.8-2$ & 0.4 \\
\hline 50 & $40-60$ & 260 & 30 & 2.9 & $5.5-6.5$ & $2-2.3$ & 0.5 \\
\hline 60 & $60-100$ & 250 & 30 & 3 & $5.5-6.5$ & $2-2.5$ & 0.5 \\
\hline 80 & $60-100$ & 210 & 40 & 3.1 & $6-6.5$ & $2.2-2.5$ & 0.5 \\
\hline 100 & $60-100$ & 190 & 50 & 3.3 & 6.5-7.5 & 2.5 & 0.5 \\
\hline
\end{tabular}

- $\quad$ significant adjustment of the upper edge of the cut surface,

- surface of the cut area covered with iron oxides,

- a scored cutting surface.

\section{Reasons of deformations on the cut surface of semiproducts}

In case of thickness of $20 \mathrm{~mm}$ it was shown that the final width of the cutting kerf was larger by $0.6 \mathrm{~mm}$ than the parameter stated by the producer. The deviation is quite a significant issue from the standpoint of accuracy of semiproducts' paramaters. High cutting speed caused deviations in uprightness of surfaces of semiproducts. Exceedingly high pressures of heating gases caused melting of surface of the cut material.

Testing of nozzles A-SD in thickness of metal sheet $25 \mathrm{~mm}$ showed that the final width of the cutting kerf was larger by $0.2 \mathrm{~mm}$ than recommended by the producer. High cutting speed and high pressure of a heating flame caused miniature oxide-bases balls in the lower part of the cut surface, sidelong scoring appeared on the upper part of the cut surface.

Catalog cutting proportions were not confirmed even in the material thickness of $30 \mathrm{~mm}$ and $40 \mathrm{~mm}$. It was again proven that cutting speeds and pressures of gases were overestimated and caused the above-mentioned deviations. In material thickness of $30 \mathrm{~mm}$ and $40 \mathrm{~mm}$ it was shown that optimal cutting speeds are lower by $25 \%$. Widths of kerfs were identical and are very similar to those in the catalog. Pressures of heating gases were lower by one quarter in comparison with the catalogue. The optimal pressure of cutting oxygen in material thickness of $30 \mathrm{~mm}$ was by $15 \%$ lower and in the thickness $40 \mathrm{~mm}$ similar to catalog parameters.

The closest parameters in comparison with those stated in the catalogue were the results of nozzles A-SD in the thickness of $50 \mathrm{~mm}$ and 60 $\mathrm{mm}$. Except for cutting speed that was lowered according to the catalogue by $20 \%$ in thickness of $60 \mathrm{~mm}$ and $27 \%$ in thickness of $50 \mathrm{~mm}$, nozzles A-SD reached balanced parameters in other spheres. Widths of kerfs made by nozzles A-SD were identical with those stated in the catalogue. The nozzles reached very similar or the same values in pressures of heating gases or cutting oxygen. In case of the thickest materials, $80 \mathrm{~mm}$ and $100 \mathrm{~mm}$ there originated similar deformations on the cut surface as in case of thinner materials. These deformations were caused especially by high cutting speed which was optimized to parameters lower by $21 \%$ or even $24 \%$. Deviations of the required parameters of cutting kerfs were by 0.1 up to $0.3 \mathrm{~mm}$. Optimal pressures of heating gases were strikingly similar to the pressures stated by the produces. However, the stated pressure of cutting oxygen was by $13 \%$ up to $15 \%$ higher than the optimal pressure.

\section{Further knowledge found during testing of nozzles A-SD}

During the research we found out that cutting proportions do not depend on chemical composition of steels. That means that stated cutting proportions can be applied to all kinds of standardly cut steels. In case of nozzles A-SD it was showed that burning off the metal sheet inside the surface is suitable to perform up to the thickness of 80 $\mathrm{mm}$. In thickness above $80 \mathrm{~mm}$ it is suitable to perform burning off on the edge of the material. Furthermore, the rule of the use of a nozzle with 
a higher range for materials on the limits of the range of the nozzlewas also confirmed,i.e. the use of the nozzle with the range from $60 \mathrm{~mm}$ up to 100 $\mathrm{mm}$ for steel sheet thickness of $60 \mathrm{~mm}$ it is more economical from the view point of gas saving.

For material thicknesses up to $100 \mathrm{~mm}$ the optimal distance of the nozzle from material is between 2 and $3 \mathrm{~mm}$, in thicknesses over 100 $\mathrm{mm}$, from 3 to $4 \mathrm{~mm}$.

\section{Application of knowledge in practice}

The stated research has shown that catalog cutting parameters for steel oxygen cutting by the producer of the nozzles A-SD were strikingly overestimated. The parameters cannot be used in machine oxygen cutting where there is necessary the final quality of cut surfaces. The research set optimal cutting proportions for steel cutting by the nozzles A-SD by the producer RHONA. The knowledge can be directly applied in machine cutting with the use of nozzles A-SD without a repeated tedious processof optimal cutting proportionsselection. The final quality of the cut surface, according to newly-established paramaters, reaches general standards.

\section{Acknowledgement}

The article was made under support grant project KEGA 022ŽU-4/2017 Implementation of on-line education in thearea of precise technologies with an impacton educational process to increase skills andflexibility of students of engineering fields of study.

\section{REFERENCES}

1. Čuboňová N. and Kuric. I. Data structures implementation of the protocol STEP-NC at CNC machines programming. 16(3A), 2014, 176-183.

2. Czán A., Sajgalík M., Holubjak J. and Kouril K.Studying of cutting zone when finishing titanium alloy by application of multifunction measuring system. Manufacturing Technology, 13(4), 2013, 428-431

3. Hloch S., Hlaváček J., Vasilko K., Cárach J., Samardžić I., Kozak D., Hlavatý I., Ščučka J.J., Klich, J. and Klichová, D.Abrasive WaterJet (AWJ) Titanium Tangential Turning Evaluation. Metalurgia, 53(4), 2014, 537-540.
4. http://www.linde-gas.sk [cit. 2010-3-21].

5. http://www.matnet.sav.sk/index.php?ID=373- [cit. 2009-11-11].

6. http://www.pierce.cz/scorpion.htm [cit. 17.2.2017].

7. Krejčí L., Hlavatý I. and Ševčíková X.Transition Zones Study of the Heterogenous Welded Joints. Metal 2013. Brno, Czech Republic 2013, 785-789.

8. Náprstková N., Cais J., Stančeková D. and Kraus, P. Analysis of the composition of selected interts using electron microscopy. Manufacturing Technology, 16(5), 2016, 1063-1067.

9. Panda A., Duplak J., Hatala M., Krenicky T. and Vrabel P. Research on the durability of selected cutting materials in the process of turning carbon steel. MM Science Journal, October, 2016, 1086-1089.

10. Petru J., Schiffner J., Zlamal T, Sadílek, M. and Stancekova D. Investigations of cutting tool wear while machining inconel 718. Manufacturing Technology, 15(3), 2015, 396-403.

11. Radvanská A., Hreha P., Knapčíková L.,Petrů J., Zlámal T. and Monka, P. Influence of focusing tube wear on vibrations and surfaces roughness. Technical Gazette, 22(2), 2015. 271-278.

12. Rudawska A., Danczak I., Muller M. and Valasek P. The effect of sandblasting on surface properties for adhesion. International journal of adhesion and adhesives, vol. 70, 2016, 176-190.

13. Sadílek M.,Kratochvíl J.,Petrů J., Cep R.,Zlámal T.andStančeková D.Cutting tool wear monitoring with the use of impedance layers. Tehnicki Vjesnik, 21(3), 2014, $639-644$.

14. Sága M., Vaško M., Čuboňová N. and Piekarska W. Optimisation Algorithms in Mechanical Engineering Applications.Harlow: Pearson. 2016.

15. Šajdlerová I., Gregušová, M. and Schindlerová, V. Potential of value stream mapping utilization in the seamless steel tubes manufacturing process. METAL 2015: 24th International Conference on Metallurgy and Materials, Brno, Czech Republic 2015, 2056-2064.

16. Sapieta M.,Sapietova A. and Deky, V. Comparison of the thermoelastic phenomenon expressions in stainless steels during cyclic loading. Metalurgija, 56(1-2), 2017, 203-206.

17. Stancekova D.,Semcer J., Sajgalik M. and Janota M. Heat-Affected Zone of Plasma of Laser Cut Materials. Manufacturing Technology, vol. 3, 2014, 451-456.

18. Stuchlý V., Poprocký R. and Kaczmarek M. Reliability evaluation as a means of increasing the efficiency of equipment maintenance. Advances in Science and Technology Research Journal, vol. 10, no. 32, 2016, 40-46. 